\title{
Gypsum partitions in medical rooms
}

\author{
Tomasz Kania,", and Henryk Nowak \\ Faculty of Civil Engineering, Wroclaw University of Science and Technology, \\ Wybrzeze Wyspianskiego 27, 50-370 Wroclaw, Poland
}

\begin{abstract}
In the time of intensive industry development, our natural environment will not manage alone with millions of tons of pollutants introduced into the atmosphere. The more harmful substances we are able to adapt, the smaller are the side effects of our activities. Synthetic gypsum is being produced as the by-product of processes aimed at protecting the environment against the harmful effects of sulphur dioxide from the energy industry. Gypsum products are being mainly used for making non-loadbearing walls inside buildings and for finishing the surfaces of internal partitions. Medical facilities, due to special conditions of use, must meet a wide range of requirements in this regard.

Paper presents selected requirements for medical rooms in the field of acoustic insulation of walls from airborne sounds and protection of users against harmful ionizing radiation. The methods of execution of the partitions with the use of gypsum products that meet these requirements have been presented.
\end{abstract}

\section{Introduction}

Protection of man's natural environment is a superior aim of man's activity. At the time of intensive development of industry, nature will not cope on its own with millions of tons of pollution constantly introduced into the atmosphere. The more industrial pollution can be utilized, the smaller will be the side effects of contamination. During the past twenty years, in the Polish power engineering industry based on combustion of black and brown coal deposits, revolutionary technological changes connected with purification of exhaust fumes were implemented. Development of exhaust fume desulphurization methods took place after signing of the first international agreements by Poland forcing the reduction of sulphur dioxide emissions into the atmosphere. Among all exhaust fume desulphurization methods, the wet lime method has become the most common. In this process, sulphur dioxide is absorbed from an alkaline slurry suspension. In the case of using a calcium-based neutralizing reagent, synthetic gypsum is a by-product of exhaust fume desulphurization. Currently, a considerable amount of cheap synthetic gypsum is appearing in the market which is often processed in the direct neighbourhood of the power plant [1].

Medical areas in hospitals, medical and dental offices, laboratories and x-ray rooms_must fulfil additional requirements, such as those regarding the acoustic properties of partitions insulating from air and impact sounds, low radioactivity of burning materials and protection

\footnotetext{
${ }^{*}$ Corresponding author: tomasz.kania@pwr.pdu.pl
} 
properties concerning building products made from a calcium sulphate base with respect to their acoustic properties insulating from air sounds between rooms and with respect to their utilisation in partitions protecting from ionizing radiation.

\section{Requirements concerning building partitions in medical spaces}

Requirements concerning the technical properties of building partitions in medical spaces are regulated by relevant legal and executive acts. This chapter presents and describes in detail selected admissible values regarding the technical properties of partitions and building products in medical spaces with respect to airborne sound insulation, radioactivity and protection from radiation.

\subsection{Airborne sound insulation}

The national requirements concerning minimum acoustic insulating properties of walls between rooms in medical facilities are presented in table 1.

Table 1. Polish acoustic demands for walls in medical rooms [2]

\begin{tabular}{|c|c|c|}
\hline No. & $\begin{array}{l}\begin{array}{l}\text { Walls between rooms in hospital buildings and healthcare } \\
\text { facilities: }\end{array} \\
\end{array}$ & $\begin{array}{c}\text { Required value of } \\
R^{\prime}{ }_{A 1} \text { rate }[d B] \\
\end{array}$ \\
\hline 1 & between rooms with beds in the hospital & 45 \\
\hline 2 & $\begin{array}{l}\text { between a room with beds and a corridor or hall in the hospital } \\
\text { ward }\end{array}$ & 40 \\
\hline 3 & $\begin{array}{l}\text { between units of operating rooms and other rooms in the } \\
\text { hospital }\end{array}$ & 55 \\
\hline 4 & $\begin{array}{l}\text { between intensive the medical care room (ICU) and another } \\
\text { room with beds or a corridor }\end{array}$ & 48 \\
\hline 5 & between a room with beds and a kitchen area & 50 \\
\hline 6 & $\begin{array}{l}\text { between a doctor's office, operating room, nurses' room and a } \\
\text { general passage area in the hospital }\end{array}$ & 45 \\
\hline 7 & $\begin{array}{l}\text { between doctor's rooms and operating rooms, nurses' rooms } \\
\text { and between these rooms and rooms with beds in the hospital } \\
\text { or rooms of residents in the sanatorium }\end{array}$ & 48 \\
\hline 8 & between rooms of residents in the sanatorium & 48 \\
\hline 9 & $\begin{array}{l}\text { between a doctor's room, operating room, nurses' room and a } \\
\text { general passage area }\end{array}$ & 45 \\
\hline 10 & $\begin{array}{l}\text { between a room with beds in the hospital or room of residents } \\
\text { in the sanatorium, doctor's room and operating room in the } \\
\text { hospital, sanatorium, out-patient clinic and rooms with sources } \\
\text { of acoustic disturbances }\end{array}$ & $50-60^{*}$ \\
\hline \multicolumn{3}{|c|}{$\begin{array}{l}\text { * - Minimum value for walls near technical rooms. } \\
\text { The requirements should be determined individually taking into account the types o } \\
\text { disturbances. }\end{array}$} \\
\hline
\end{tabular}

The requirements presented in table 1 are expressed using the rate of weighted apparent sound reduction index with spectrum adaption term $\mathrm{R}_{\mathrm{A} 1}[\mathrm{~dB}]$ which is described using the formula (1) $[3,4]$. 
where:

$R_{w}$ is a weighted sound reduction index obtained based on tests of acoustic insulating properties of the partition in laboratory conditions $[\mathrm{dB}]$,

$C$ is a spectrum adaption term for the internal sounds of living (A-weighted Pink Noise spectrum) $[\mathrm{dB}]$,

$K_{a}$ is the value of correction accepted due to the effect of flanking transmission of sound on the value of the single number rate $R_{A I}^{\prime}[\mathrm{dB}]$.

According to the formula (1), the value of calculations concerning the weighted apparent sound reduction index with spectrum adaption term for the given partition is reduced by 2 $\mathrm{dB}$. This correction takes into account the accuracy of determining rates based on laboratory measurements, different degrees of reflecting the material and structural solution in the tested sample and potential performance inaccuracies, fulfilling the role of a safety rate for designing acoustic insulating properties of partitions [5].

The requirements presented in table 1 fall within a range from $40 \mathrm{~dB}$ for walls between a room with beds and a corridor up to more than $60 \mathrm{~dB}$ for walls separating rooms with beds or doctor's offices from technical rooms with building installation equipment.

\subsection{Radioactivity of building products}

Pursuant to national regulations concerning hazardous radiations included in the Ordinance issued by the Council of Ministers on 2 January 2007 [6], two qualification activity indices are accepted as the basis for evaluation of building products: $\mathrm{f}_{1}$ and $\mathrm{f}_{2}$, which are determined in laboratory conditions. Testing methods and evaluation criteria are included in the ITB Manual no. 455/2010 [7]. The $f_{1}$ index indicates exposure of the entire body to gamma radiation by natural radionuclides appearing in the material: potassium $\mathrm{K}-40$, radium $\mathrm{Ra}-$ 226 and thorium $\mathrm{Th}-228$. The $f_{l}$ index has a complex form taking into account the differing weight of individual radioisotopes which is presented in the formula (2).

$$
f_{l}=S_{k} /(3000 \mathrm{~Bq} / \mathrm{kg})+S_{R a} /(300 \mathrm{~Bq} / \mathrm{kg})+S_{T h} /(200 \mathrm{~Bq} / \mathrm{kg}) \quad[-]
$$

where: $\mathrm{S}_{\mathrm{K}}, \mathrm{S}_{\mathrm{Ra}}, \mathrm{S}_{\mathrm{Th}}$, is the concentration of potassium $\mathrm{K}_{40}$, radium $\mathrm{Ra}_{226}$ and thorium $\mathrm{Th}_{228}$ in $\mathrm{Bq} / \mathrm{kg}$. The safety requirement is fulfilled if $f_{1} \leq 1,2$.

The $f_{2}$ index indicates the content of radium isotope $\mathrm{Ra}_{226}$. The safety requirement, defined as the limit value of radium concentration in the building material, is presented by the formula (3).

$$
f_{2}=S_{R a} \leq 240[\mathrm{~Bq} / \mathrm{kg}]
$$

where $\mathrm{S}_{\mathrm{Ra}}$ is the concentration of radium $\mathrm{Ra}_{226}$ in $\mathrm{Bq} / \mathrm{kg}$. The safety requirement for the $f_{2}$ index is fulfilled, if the value of the $\mathrm{Ra}_{226}$ isotope in the tested material does not exceed 240 $\mathrm{Bq} / \mathrm{kg}$.

\subsection{Protection from ionising radiation}

Polish requirements regarding protection from ionising radiation emitted by medical equipment are included in regulations $[8,9,10,11]$. According to the regulations, the design of walls, ceilings, windows, doors and installed protective equipment should protect persons working in $\mathrm{x}$-ray labs from receiving radiation at a dosage exceeding $6 \cdot 10^{-3} \mathrm{~J} / \mathrm{kg}\left(10^{-3} \mathrm{~J} / \mathrm{kg}\right.$ $=1 \mathrm{mSv}$ ) per year. Persons working in $\mathrm{x}$-ray lab rooms outside of the $\mathrm{x}$-ray lab should be protected from receiving the radiation at a dosage exceeding $3 \cdot 10^{-3} \mathrm{~J} / \mathrm{kg}$ per year. Persons 
remaining in rooms outside of the x-ray lab and persons from the general population remaining in adjacent rooms should be protected from receiving radiation at a dosage exceeding $5 \cdot 10^{-2} \mathrm{~J} / \mathrm{kg}$ per year.

Calculation of the radiation dosage to which users of rooms adjacent to the x-ray lab are exposed requires knowledge of the radiation dosage emitted by the unit and calculation of the designed exposure time $t$ according to the formula (4). Calculation is made according to the probability of presence of people in shielded area, direction of x-ray beam in relation to the protective wall and designed usage time of the $\mathrm{x}$-ray machine. It is formulated in seconds per week.

$$
t=T \cdot U \cdot t_{0}[\mathrm{~s} / \text { week }]
$$

where: $T$ is a coefficient specifying the probability of people staying in a shielded area. $T$ is equal to 1 for shielded places where people stay permanently (places of continuous work, residences, places intended for children); $T$ is equal to 0,25 for shielded places used temporarily (corridors, waiting rooms, sanitary rooms);

$U$ is the rate describing the probability of directing a usable radiation beam in the direction of the calculated partition. $U$ is equal to $l$ for walls radiated using the main beam during routine work. $U$ is equal to 0.25 for walls not radiated using the main beam during routine work (when radiating beam of the x-ray device is not pointed in the direction of calculated partition).

$t_{0}$ is the maximum operating time of the radiation source per week during one shift [s/week].

Determination of the thickness for the protective layer of the wall separating rooms in which equipment emitting ionizing radiation is located requires calculation of the so called "lead thickness equivalent" corresponding to a protective layer of the material used to make the partition. In order to fulfil the requirements, the thickness of the designed protective layer which covers the wall of the protected room is also calculated.

Determination of protective layer against the primal radiation (pointed in the direction of partition) requires the calculation of parameter of multiplicity of attenuation $k$ of designed radiation by protective shield. This parameter depends on the power and amperage of radiation specific to the machine and its location from the partition and the shielded area, designed time of work of x-ray device, acceptable (allowed) radiation dose, shielding centre protective value, probability of pointing the X-ray beam on the partition and probability of people presence in shielded area. Parameter $k$ is calculated using the formula (5).

$$
k=(M \cdot J \cdot t) /\left(D \cdot l^{2}\right) \cdot y \cdot T \cdot U \quad[-]
$$

where: $M$ is the power of radiation dose at a distance of $1 \mathrm{~m}$ from the lamp source for anode current $1 \mathrm{~mA}\left[\mathrm{cJ} / \mathrm{kg} \cdot \mathrm{min}^{-1} \cdot \mathrm{m}^{2} \cdot \mathrm{mA}^{-1}\right]$;

$J$ is the amperage of the $\mathrm{x}$-ray lamp anode current $[\mathrm{mA}]$;

$t$ is the designed exposure time according to the formula 4 [s/week];

$D$ is acceptable weekly radiation dose $[\mathrm{cJ} / \mathrm{kg}]$.

$l$ is the smallest distance of the lamp source from the shielded place under agreed working conditions $[\mathrm{m}]$;

$y$ is the radiation attenuation index in the calculated centre;

$T, U$ as in the description for the formula (4).

Value of $k$ parameter and X-ray device lamp voltage allows us to estimate the demanded lead thickness equivalent. The example of dependency between $k$ parameter and lead thickness for the $\mathrm{x}$-ray lamp with voltage of $100 \mathrm{kV}$ has been shown on figure 1 [11]. 


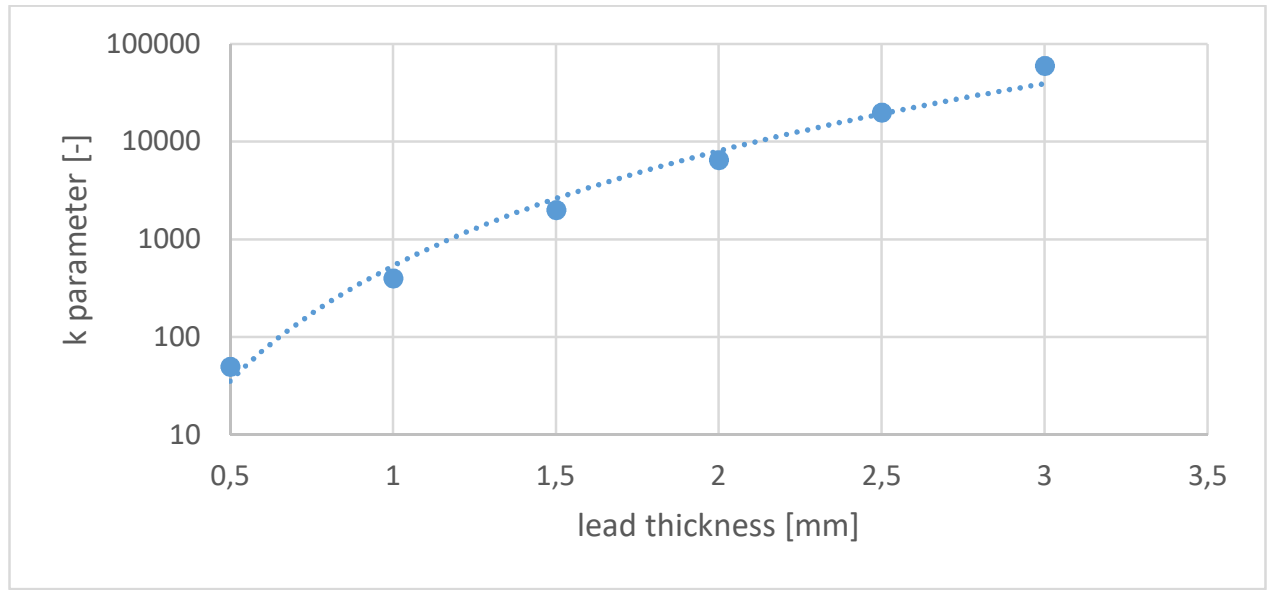

Fig. 1. Dependency between parameter of multiplicity of attenuation $k$ of designed radiation by protective shield and equivalent thickness of lead in protective shield [11]

According to information available in the literature, for the purpose of further comparative analysis it is assumed that walls separating x-rays labs, using additional shields within the operating area of radioactive equipment, should ensure protective properties equivalent to the following thicknesses of lead shields:

- $\quad 1-1.5 \mathrm{~mm}$ of lead for walls separating $\mathrm{x}$-rays labs for a voltage value of the emitting unit lamp equal to $100 \mathrm{kVp}$,

- $\quad 0.3 \mathrm{~mm}$ of lead for walls separating mammography labs for a voltage value of the emitting unit lamp equal to $30 \mathrm{kVp}$,

- $0.5 \mathrm{~mm}$ of lead for walls separating dental cephalometric labs for a voltage value of the emitting unit lamps equal to $100 \mathrm{kVp}$.

\section{Properties of gypsum walls and products}

When choosing the system of partition wall solutions in medical facilities, attention should be paid to the necessity of maintaining asepsis in their areas. For this reason, structures of walls and connections between them cannot include any hard to reach empty spaces where development of microorganisms or rodents is possible. In any spaces requiring frequent disinfection, walls should be easily washable and easy to keep clean using generally available cleaning agents. For this reason, it is not recommended to make this type of partitions using the skeleton system with filling made of mineral or organic wool. In the later part of this chapter, gypsum walls made using the brick system will be considered.

\subsection{Acoustic insulating properties of gypsum walls}

According to tests conducted by the authors and completed research in the literature, the value of correction assumed due to the effect of flanking transmission of sound $K_{a}$ for walls made of gypsum elements connected in a flexible way with all partitions along their circumference falls within the range from 1 to $3 \mathrm{~dB}$ (for massive circumferential partitions) $[3,5,12]$. The weighted sound reduction index with spectrum adaption term $\mathrm{C}$, for single walls made of synthetic gypsum can be approximated using the formula (6) [1].

$$
R_{A 1}=11,54 \ln \left(m^{\prime}\right)-11,95[d B]
$$


where $\mathrm{m}$ ' is the surface mass of gypsum wall. This formula is applicable to the surface mass of walls within a range from 65 to $140 \mathrm{~kg} / \mathrm{m}^{2}$. Dependence between surface mass of the partition and its acoustic insulating properties is presented in fig. 2 .

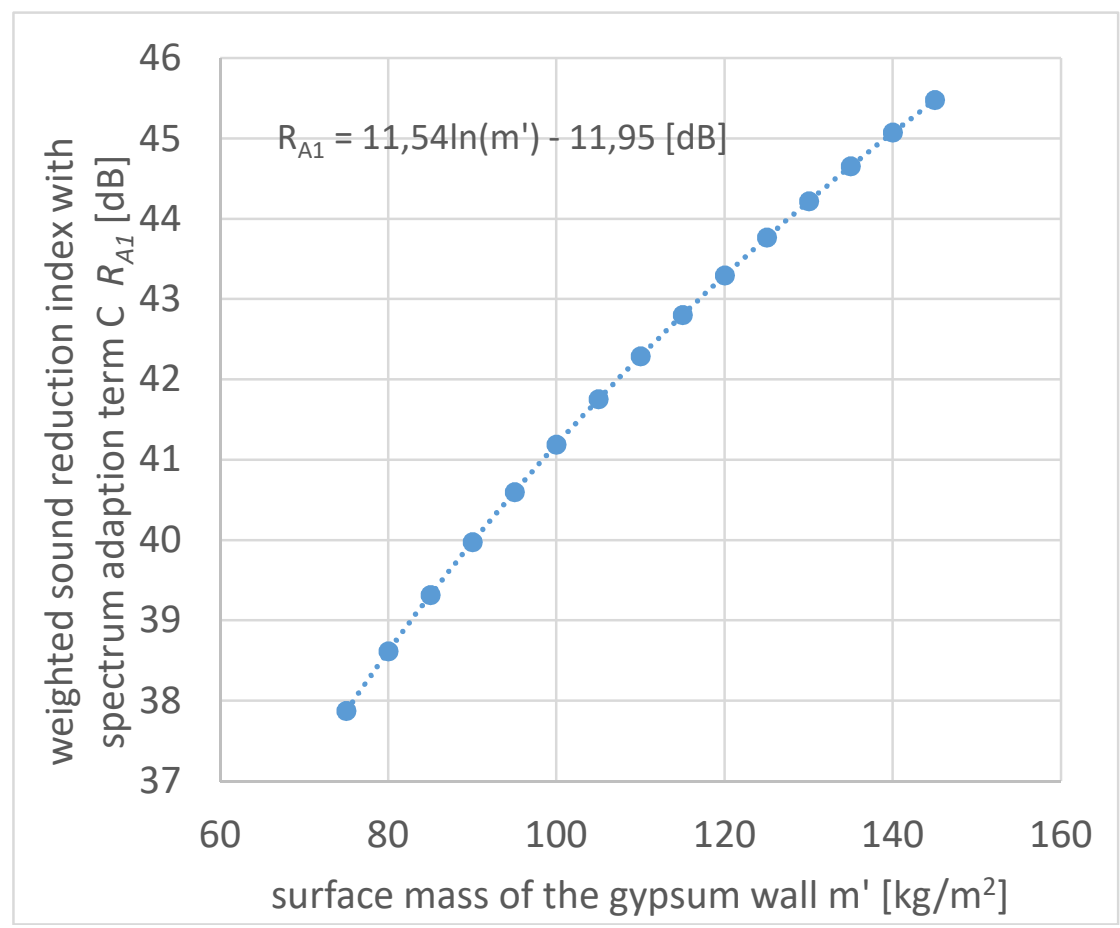

Fig. 2. Dependency between acoustic insulation and surface mass of gypsum solid walls elastically connected on their peripheries

While analysing the empirical curve shown in fig. 2, it can be concluded that the the rate of weighted apparent sound reduction index with spectrum adaption term $C$ of a single gypsum wall, thickness $10 \mathrm{~cm}$ and bulk density of $1250 \mathrm{~kg} / \mathrm{m}^{3}\left(\mathrm{~m}^{\prime}=1250 \mathrm{~kg} / \mathrm{m}^{2}\right)$, depending on designed circumferential partitions (excluding light skeleton partition), with the flanking transmission correction $K_{a}=1-3 \mathrm{~dB}$ falls within the range of $R_{A I}^{\prime}=39-41 \mathrm{~dB}$. Such an acoustic insulating property value is sufficient to make walls between a room with beds and a corridor or hall in the hospital ward.

The erection of walls between rooms with beds and other rooms requires application of brick sandwich walls. A horizontal cross-section through the sandwich wall, thickness 240 $\mathrm{mm}$ and surface mass of $170 \mathrm{~kg} / \mathrm{m}^{2}$, is shown in figure 3 .

Such a structural solution allows the rate of the approximated evaluation of specific acoustic insulating property R' ${ }_{\mathrm{A} 1}$ within a range of $50 \mathrm{~dB}\left(K_{a}=3 \mathrm{~dB}\right)$ to $52 \mathrm{~dB}\left(K_{a}=1 \mathrm{~dB}\right)$ to be obtained, and when a wall with expansion joints is made along its entire circumference (e.g. on structural expansion joints of the building) within a range from 55 to $57 \mathrm{~dB}$. 


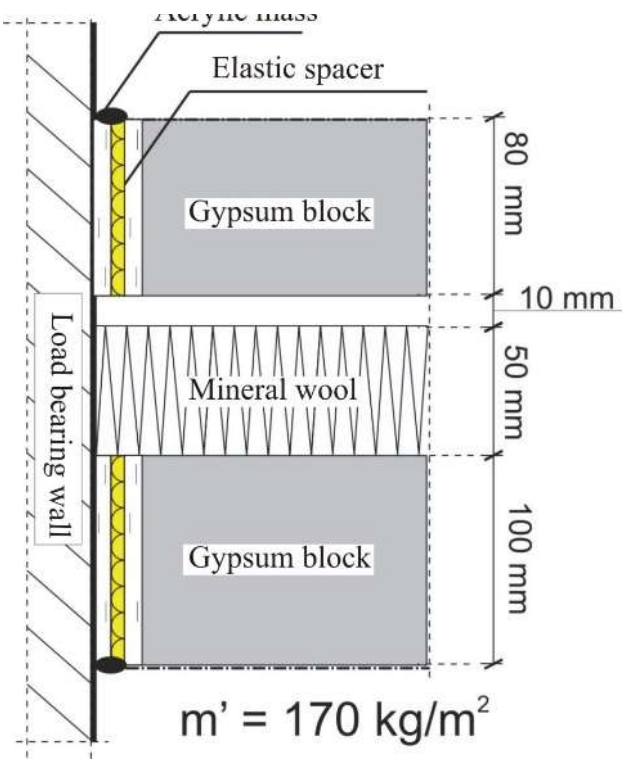

Fig. 3. Detail of gypsum double layer partition connection with adjacent wall (cross section)

With appropriate design of the rooms and particular consideration of the acoustic requirements presented in chapter 2.1, the described solution for the sandwich wall allows fulfilment of all acoustic requirements for rooms in medical facilities, except for walls separating technical rooms with sources of acoustic disturbance for which, with high designed intensity of sound coming from the equipment, the required acoustic insulating property may exceed $60 \mathrm{~dB}$.

\subsection{Radioactivity of gypsum products}

The influence of elements made of gypsum obtained in the process of exhaust fume desulphurization using the wet calcium lime method and gypsums of natural origin on living organisms and the environment has been researched and presented in many studies [1, 12, $13,14,15]$. With respect to chemical composition, gypsum from exhaust fume desulphurization using the wet lime method shows a high level of pureness - in most cases, much higher than in natural gypsum.

Table 2 presents the values of radioactivity rates for natural gypsums occurring in Poland and synthetic gypsum obtained from desulphurization of exhaust gases from brown coal combustion.

Table 2. Comparison of radioactivity rates for natural and synthetic gypsums $[14,15]$

\begin{tabular}{|l|c|c|}
\hline $\begin{array}{l}\text { Radioactivity } \\
\text { rate } \\
\text { (average values) }\end{array}$ & $\begin{array}{c}\text { Type of gypsum } \\
\text { stone } \\
\text { (Nida valley) }\end{array}$ & $\begin{array}{c}\text { Synthetic gypsum } \\
\text { (brown coal) }\end{array}$ \\
\hline $\mathrm{f}_{1}[\mathrm{~Bq} / \mathrm{kg}]\left(\mathrm{K}_{40}, \mathrm{Ra}_{226}, \mathrm{Th}_{232}\right)$ & 0.08 & 0.02 \\
\hline $\mathrm{f}_{2}[\mathrm{~Bq} / \mathrm{kg}]$ (radon emanation) & 15.2 & 4.47 \\
\hline
\end{tabular}

The values of radioactivity rates for natural and synthetic gypsums are very low with respect to requirements imposed on building products used in medical areas and in large volume buildings. Radioactivity of synthetic gypsum from desulphurization of exhaust fumes from 
brown coal combustion is more tnan tnree tımes lower tnan trom gypsum stone or natural origin. Both synthetic and natural gypsum belong to the group of materials with the lowest radioactivity, with a level similar to Vistula sand.

\subsection{Gypsum products as protection from ionising radiation}

The protective properties of building materials from ionising radiation is expressed using the multiplicity index of material thickness versus lead thickness characteristic for specific operating voltage of an x-ray lamp [16]. Table 3 presents equivalent values of thickness for selected building materials with respect to lead, thickness of $1 \mathrm{~mm}$, at an $\mathrm{x}$-ray lamp voltage of $100 \mathrm{kV}$.

Table 3. Equivalent values of thickness for selected building materials with respect to lead, thickness of $1 \mathrm{~mm}$, at an $\mathrm{x}$-ray lamp voltage of $100 \mathrm{kV}[11,17]$.

\begin{tabular}{|c|l|c|}
\hline L.P. & \multicolumn{1}{|c|}{ Building material and its density } & $\begin{array}{c}\text { Equivalent thickness of material } \\
\text { with respect to lead, thickness of } \\
\mathbf{1 ~ m m , ~ a t ~ a n ~ x - r a y ~ l a m p ~ v o l t a g e ~} \\
\text { of 100 kV } \\
\text { [mm] }\end{array}$ \\
\hline 1 & Gypsum, density $900 \mathrm{~kg} / \mathrm{m}^{3}$ & 200 \\
\hline 2 & Gypsum barytic plaster, density $2000 \mathrm{~kg} / \mathrm{m}^{3}$ & 14 \\
\hline 3 & Gypsum plasterboard with baryte insert & 18 \\
\hline 4 & Concrete, density $2200 \mathrm{~kg} / \mathrm{m}^{3}$ & 75 \\
\hline 5 & Solid ceramic brick, density $1900 \mathrm{~kg} / \mathrm{m}^{3}$ & 100 \\
\hline 6 & Hollow ceramic brick, density $1400 \mathrm{~kg} / \mathrm{m}^{3}$ & 165 \\
\hline 7 & Silicate brick, density $1600 \mathrm{~kg} / \mathrm{m}^{3}$ & 200 \\
\hline 8 & Aerated concrete, density $600 \mathrm{~kg} / \mathrm{m}^{3}$ & 270 \\
\hline 9 & Cement barytic plaster, density $3200 \mathrm{~kg} / \mathrm{m}^{3}$ & 14 \\
\hline 10 & Steel, density $7900 \mathrm{~kg} / \mathrm{m}^{3}$ & 6,4 \\
\hline
\end{tabular}

It can be concluded from the data shown in table 3 that in order to obtain properties screening ionising radiation comparable to a lead plate $1 \mathrm{~mm}$ thick, commonly erected systems of walls made of autoclaved aerated concrete $600,270 \mathrm{~mm}$ thick, full walls made of ceramic brick, $100 \mathrm{~mm}$ thick, or gypsum walls, $200 \mathrm{~mm}$ thick, can be used. Such protection can also be achieved using products specially designed for it, for example with the addition of barytic salts. For instance, cladding made of two drywalls with a barytic insert $(2 \cdot 12.5 \mathrm{~mm})$ constitutes protection equivalent to a lead plate $1.4 \mathrm{~mm}$ thick. Barytic plasters contain baryte powder, mineral fillers, cement or gypsum binder, plastifier and water. These mixtures are used as protection from $\mathrm{x}$-ray radiation. It is assumed that a layer of cement and baryte plaster, $2 \mathrm{~cm}$ thick, approximately substitutes for $1.5 \mathrm{~mm}$ of lead. Baryte powder contains baryte sulphate. This mineral is excavated in Poland in the town of Boguszów-Gorce in Lower Silesia. It is not chemically aggressive, it dissolves only in sulphuric acid. Therefore, there are not any counterindications to its use in a gypsum foundation. The problem, however, is high bulk density of hardened plaster amounting to $2700-3200 \mathrm{~kg} / \mathrm{m}^{3}$. Plaster is applied in layers of 6-8 $\mathrm{mm}$ up to a total thickness of $20-30 \mathrm{~mm}$. Therefore, its surface mass is approx. $60-90 \mathrm{~kg} / \mathrm{m}^{2}$. There is a risk that such a heavy layer will loosen from the surface of gypsum walls, even if priming agents based on silica sand are used. For this reason, in such a case a 
more reliable solution is to make x-ray shields using finished slabs, for example drywall panels with baryte insert. This technology is faster, cleaner and does not involve the risk of cracking or loosening.

\section{Summary}

The study presents requirements regarding acoustic insulating properties and protection from radiation for walls in medical facilities. Values required with respect to acoustic properties insulating from air sounds for walls between rooms are considerably higher than for vertical partitions in buildings intended for residential or office purposes. This results directly from the intended application of the rooms they refer to. Synthetic gypsum is a pure and ecological product appearing as a side product of the process of desulphurizing exhaust fumes using the wet lime method. The characteristic feature of building products made of synthetic gypsum is low natural radioactivity compared to other commonly used building materials.

The results of work presented in this study indicate that brick walls made of gypsum elements, with their structure and surface mass adapted, fulfil the requirements for medical rooms concerning acoustic insulating properties. Attention should be drawn to the described sandwich layer made of gypsum blocks, with relatively low surface mass $170 \mathrm{~kg} / \mathrm{m}^{2}$, for which it is possible to the rate of weighted apparent sound reduction index with spectrum adaption term $\mathrm{R}_{\mathrm{A} 1}$ (taking into account lateral transmission of sound) within a range from 50 to $57 \mathrm{~dB}$.

Application of modified products based on synthetic gypsum with the addition of baryte powder allows erection of walls in rooms and spaces with equipment emitting ionising radiation. Depending on the design of the protected walls and the thickness of screening material resulting from calculations, in this case baryte gypsum plasters or drywall panels with baryte core made on steel grid can be used. This type of protection, 20 to $50 \mathrm{~mm}$ thick, is sufficient to protect users of exposed facilities in most cases of designed protective walls.

\section{References}

1. T. Kania, Researches on the causes of cracking and on fire resistance and acoustic insulation of synthetic gypsum partition walls (Wroclaw University of Technology, 2014)

2. PN-B-02151-3: 2015-10 Protection against noise in buildings - Part 3: Requirements for sound insulation of partitions in buildings and building elements [Polish standard]

3. B. Szudrowicz, Mat. Bud., 11, 71-76 (2008)

4. L. Dulak, Izolacje, 6, 43-49 (2011)

5. B. Szudrowicz, Methods of calculation of acoustic insulation between rooms in a building according to PN-EN 12354-1: 2002 and PN-EN 12354-2: 2002 (ITB, Warsaw, Poland, 2016)

6. Dz. U. [Journal of Laws] from 2007 No. 4, item 29 with all changes, Poland

7. ITB Instruction No. 455/2010 ITB, Warsaw, (2010)

8. Dz. U. [Journal of Laws] from 2011 No. 51, item 265 with all changes, Poland

9. Dz. U. [Journal of Laws] from 2006 No. 180, item 1325 with all changes, Poland

10. Dz. U. [Journal of Laws] from 2007 No. 42, item 276 with all changes, Poland

11. PN-J-80001:1986 Materials and protective equipment against $X$ and gamma radiation - Calculation of permanent shields [Polish standard]

12. T. Kania, Mat. Bud., 10, 40-41 (2006) 
13. F. Aguilar, U. Charrondiere, B. Dusemund, P. Galtier, J. Gilbert, D. M. Gott, S. Grilli, R. Guertler, G. E. N. Kass, J. Koenig, C. Lambré, J.-C. Larsen, J.-C. Leblanc, A. Mortensen, D. Parent-Massin, I. Pratt, I. Rietjens, I. Stankovic, P. Tobback, T. Verguieva, R. Woutersen, EFSA, 814, 1-9, (2009)

14. M. Krawczyk, Natural radioactivity of raw materials and building materials according to the actual control tests (ITB, Warsaw, Poland, 1984)

15. J. Mikoś, Mat. Bud., 10, 4-6, (1996)

16. M. A. Boyd, The Confusing World of Radiation Dosimetry (U.S. Environmental Protection Agency, 2009)

17. Radiation Shielding Requirements for Diagnostic X-ray Facilities (Radiation Health Branch, Nedlands WA 6009, 2004) 